\title{
Long-Term Benefits of Percutaneous Anatomical Restoration of Vertebral Compression Fractures Linked to Malignancy
}

\author{
David Cesar NORIEGA ${ }^{1}$, Antonio KRÜGER ${ }^{2}$, Ruben Hernandez RAMAJO ${ }^{1}$, Francisco ARDURA ${ }^{1}$, MariFe MUNOZ ${ }^{3}$, \\ Soner SAHIN ${ }^{4}$
}

${ }^{1}$ Valladolid University Hospital, Spine Unit, Department of Orthopedic, Valladolid, Spain

${ }^{2}$ Marburg University, Department of Trauma, Marburg, Germany

${ }^{3}$ Valladolid University Hospital, Department of Investigation, Valladolid, Spain

${ }^{4}$ Derince Research and Teaching Hospital, Department of Neurosurgery, Kocaeli, Turkey

\section{ABSTRACT}

AIM: To evaluate the efficacy, feasibility and safety of a percutaneous anatomical vertebral body reduction for the treatment of VCF (vertebral compression fracture) linked to malignancy. Vertebroplasty and percutaneous kyphoplasty have played essential roles in the treatment of painful vertebral metastasis, although there are few reports with long survival that have evaluated the long-term efficacy, adjacent fractures and vertebral body (VB) re-collapse associated with these procedures. We aimed to evaluate the longterm efficacy and the complications associated with malignancy and changes in spinal biomechanics.

MATERIAL and METHODS: The retrospective study examined 32 patients with osteolytic VCF due to malignant infiltration of the vertebral body. A visual analogue scale, the EQ5 and radiological analysis (i.e., X-ray and CT scan) were used to assess back pain, quality of life and complications.

RESULTS: Statistically significant reductions in anterior and central vertebral body heights $(6.2 \mathrm{~mm}-19.6 \pm 4.2 \mathrm{~mm}-$ and $5.8 \mathrm{~mm}-$ $16.7 \pm 7.8 \mathrm{~mm}$-, respectively) that resulted in reductions of the regional Cobb angles exceeding $30 \%$ were observed. There was also a statistically significant improvement in quality of life. The average survival was longer than those reported in most published articles, and the average follow-up period was 30.9 months.

CONCLUSION: Anatomical restoration (i.e., cortical ring reduction with endplate rebalancing) is potentially beneficial for a wellselected group of patients with spine metastases and long life expectancies because this procedure avoids the complications typical of these types of treatments (e.g., leakage, adjacent fractures and re-collapse).

KEYWORDS: Percutaneous anatomical restoration, PMMA, Spine VCF, Malignant disease, Minimally invasive procedure

\section{INTRODUCTION}

Spine disease due to malignant lesions is common among cancer patients. The incidence of spine malignant disease varies from $30 \%$ to $70 \%$, depending on the primary tumor $(14,30)$, although not all of these cases are symptomatic. The incidence of vertebral compression fracture (VCF) in multiple myeloma is $24 \%, 14 \%$ in breast cancer and $6 \%$ among prostate cancer. Approximately $10 \%$ of lung cancer patients will develop spine symptoms, and approximately $40 \%$ to $70 \%$ of these patients will have multiple-level involvement $(1,28$, 34).

The development of VCF associated with malignancy deteriorates quality of life and increases pain, sagittal imbalance and abdominal and respiratory problems $(2,41)$. All of these symptoms are of great importance when dealing with the osteoporotic population (18) and are even more relevant for the cancer population $(13,19,20,22,33)$. 
The biomechanical changes that occur after a VCF predispose the maintenance an increase of clinical problems, such as chronic pain, respiratory pathology $(9,37,40)$ and abdominal disease accompanied by the development of early satiety (36). Thus, attending to these types of problems in cancer patients is particularly important to avoid respiratory infections or deterioration in the quality of life due to the previous weight loss and immunosuppression that they may have suffered.

Previous publications have focused on pain treatment in this group of patients (32) and not on evaluations of methods to control the biomechanical changes and the clinical consequences of these changes $(9,37,40)$. Due to an increase in the life expectancy of this group of patients $(3,7,10,19,20)$, these biomechanical changes are increasingly likely to occur and result in clinical symptoms.

Given our current knowledge, does it make sense to plan anatomical restorative treatments for patients with VCFs related to cancer?

The objective of this clinical study was to analyze whether anatomical restorations (i.e., cortical height reduction and endplate reduction) of VCFs caused by malignant lesions affect pain control and clinico-radiological complications over a long-term follow-up.

\section{MATERIAL and METHODS}

A retrospective study from January 2009 to December 2012 that included all patients who underwent surgery for malignant VCF was performed under the approval of the Ethics Committee of our institution.

During the period of the study, 32 consecutive patients with osteolytic malignant disease of the spine who had a VCF underwent surgeries that were performed on a total of 52 vertebral levels. There were 18 males and 14 females in our sample. The average time between the cancer diagnosis and the occurrence of the VCF was 25.9 months (0-164). A total of 52 levels were involved, and the hematologic group contained a greater number of patients who were affected on multiple levels; $62.5 \%$ of the patients with multiple level involvement belonged to this group, but the difference between these groups was not statistically significant $(p=0.12)$. The thoracolumbar junction was the most affected area in both groups and at both the single and multiple levels (Table I).

The average follow-up time was 19.7 months (2-50).

Fourteen patients had a hematologic disease; 9 cases had multiple myeloma, and 5 cases had lymphoma. In the other 18 patients, the primary tumors were in the lung (1 case), gastrointestinal ( 7 cases), melanoma (1 case), in the breast ( 3 cases), seminoma ( 1 case), mesothelioma (1 case), in the bladder ( 1 case), and in the prostate ( 3 cases). The vertebral segments most frequently affected were $\mathrm{T} 12$ and $\mathrm{L} 1$ in both groups.

\section{Surgical Technique}

Anatomical restorations were achieved via minimally invasive cementoplasty surgery, which consists of reducing both the cortical ring and the endplate of the vertebra through the introduction of two titanium cranio-caudal expandable implants (SpineJack ${ }^{\circledR}$, Vexim SA, Balma, France) (Figure 1) into the vertebral body through a transpedicular approach, under general anesthesia, to reposition the end plate fragments into their anatomical positions to achieve a full correction of the vertebral body and to control biomechanical changes in the spine. Posterior fixation was accomplished with high viscosity polymethyl methacrylate (PMMA) cement $(400 \mathrm{~Pa})$ with zirconium oxide to improve visibility (Figure 2A-C) $(26,27)$.

\section{Evaluation of Results}

The outcome measures used to evaluate our results are detailed below:

1. The efficacy of the procedure across the entire group was evaluated using visual analogue scale (VAS) pain score: preoperative and postoperative, at 12 months follow-up, and at final follow-up.

2. EQ5 quality of life: preoperative and at 6- and 12 months follow-up.

3. Survival analysis.

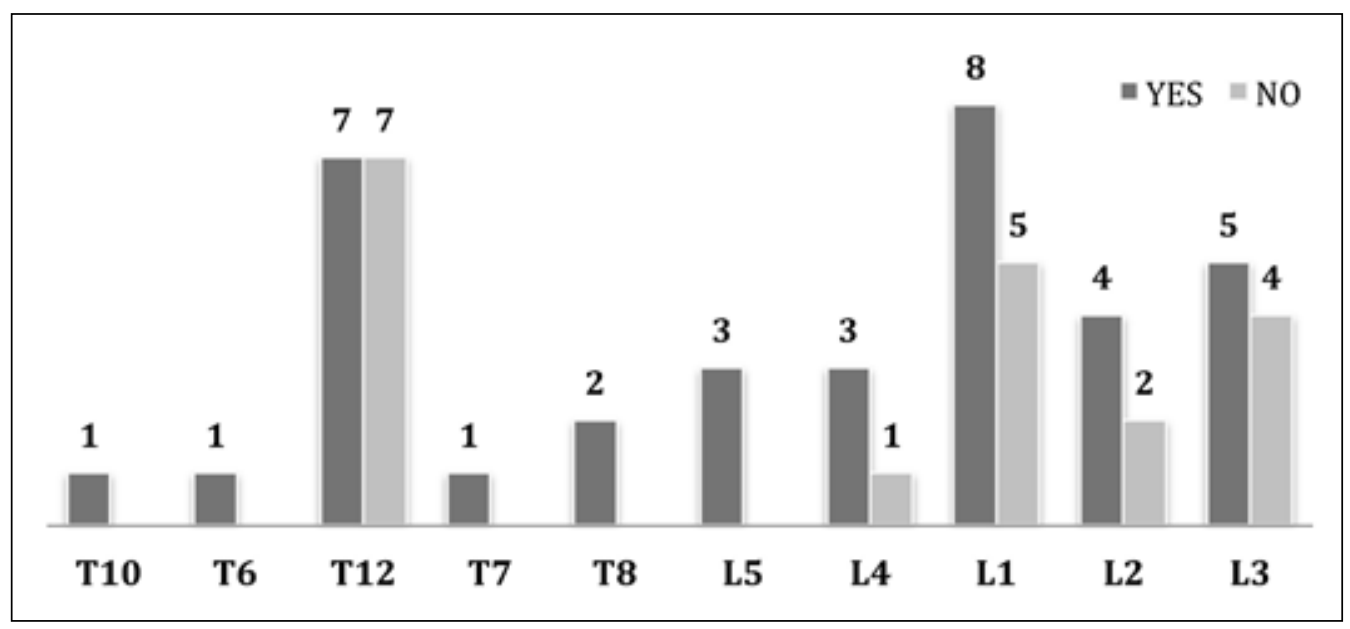

Table I: Single and multiple VCF distributions by levels. (YES= multilevel / $\mathrm{NO}=$ single level). 
4. Radiological analyses via standing X-ray in both the anteroposterior (AP) and lateral planes and preoperativepostoperative height definition computed tomography (CT) scans (1 $\mathrm{mm}$ slices) including the following:
a. anterior height
b. central height
C. posterior height

5. Regional Cobb angle (2 vertebrae above - 2 vertebrae below).

6. Complications: Cement leakage, adjacent fractures, and vertebral body re-collapse.

\section{Statistical Analyses}

The normalities of the distributions of the parameters were first analyzed with Shapiro-Wilk tests. All quantitative parameters are described with averages and standard deviations, and the qualitative values are described as frequency distributions. Pearson chi-square tests were used to evaluate the associations between qualitative parameters. Comparisons of pain evolution between the preoperative (preop) and post- operative (postop) check-ups were performed with t-tests. ANOVAs were used to assess changes in pain along the four clinical controls and were performed along the period of study (i.e., preop., postop., 1 year and final follow-up). All data were analyzed with the SPSS statistical software package (version 20.0). $p<0.05$ was considered statistically significant.

\section{RESULTS}

\section{Pain Scores}

The average preop VAS value was 7.15 , the average postop VAS value was 1.81, the average 12-month follow-up VAS value was 1.94 and the average final follow-up VAS value was 2.24. The differences between the preop, postop, 12-month and final follow-up values were statistically significant $(p<0.001)$.

The preop VAS score (7.07) of the hematologic patients was decreased (1.88) at the first postop check-up, remained stable at the 1-year follow-up and increased slightly (2.24) at the final follow-up (22.75 months). The differences between the preop, postop and 12-month follow-up values were statistically significant (Table II).

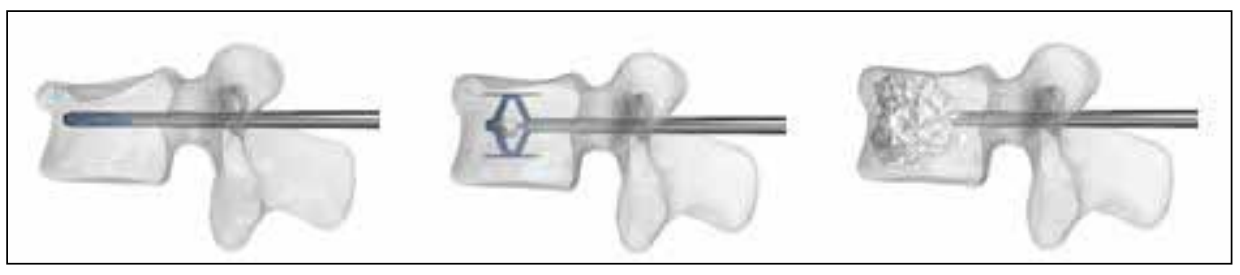

Figure 1: SpineJack® Procedure. Implant placement - Implant deployment - Cement Injection.
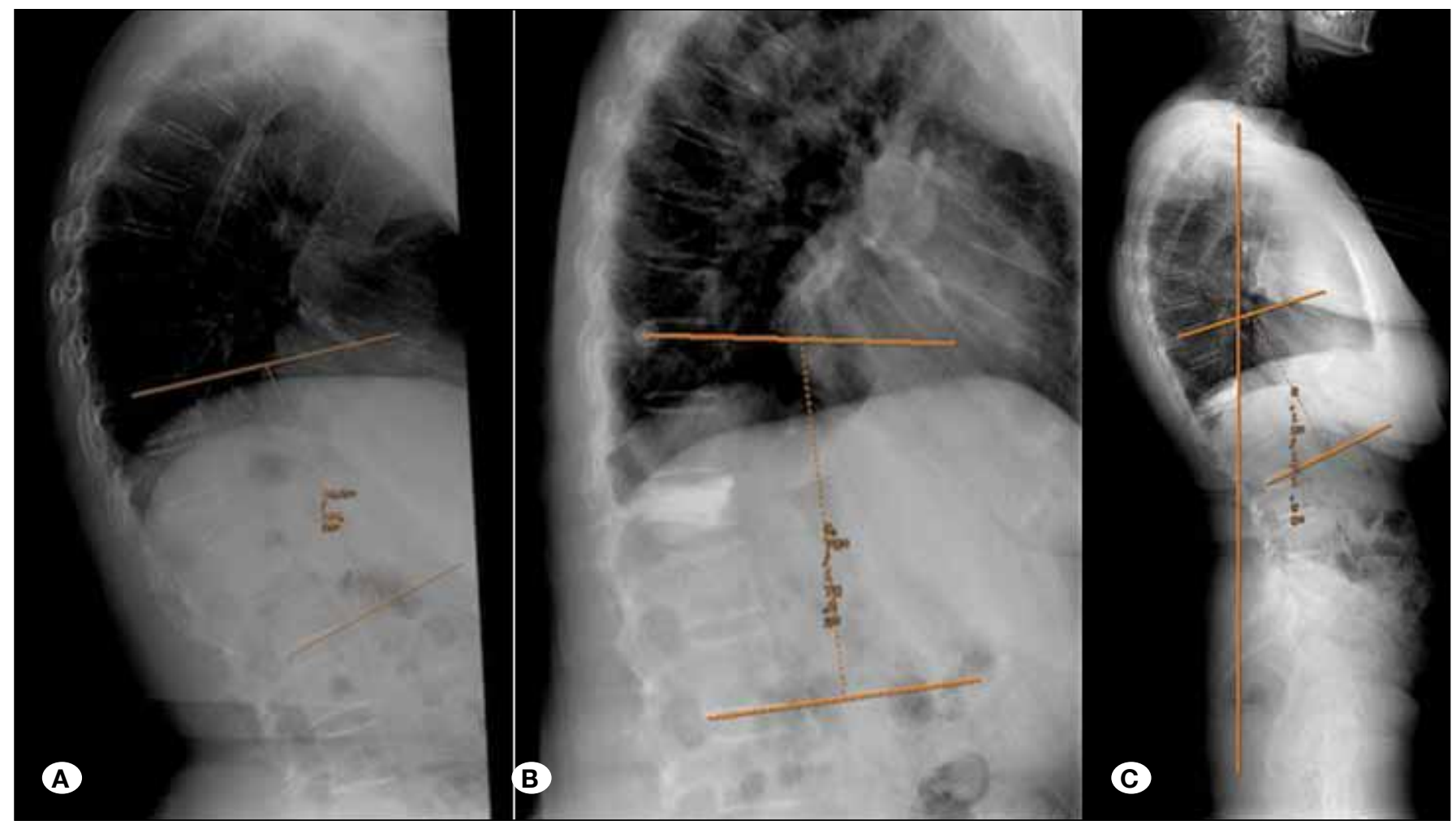

Figure 2: Breast-cancer metastasis in T12. A.1.2 fracture. X-rays at A) Preop B) Postop and C) Final check-up. 
The mean preop VAS score of the metastatic patients was 7.23. Pain decreased to 1.75 at the immediate postop, increased to 2.09 at the 12-month follow-up and increased to 2.23 at the final follow-up. The difference between the preop and postop values was statistically significant $(p<0.001)$ (Table II).

\section{Quality of Life}

The average preoperative EQ5-VAS value was 22.3 (20.1$26.3)$, and this value significantly $(p<0.005)$ increased to 68.9 (66.7-71.1) at the 6-month follow-up. At the 12-month followup, the quality of life decreased to an average of 65.6 (63.268.3) (Table III).

\section{Survival}

The average survival of the entire group was 30.9 months with a confidence interval (95\%) of 24.2-37.7. The hematologic group of patients had an average survival of 38.3 with a

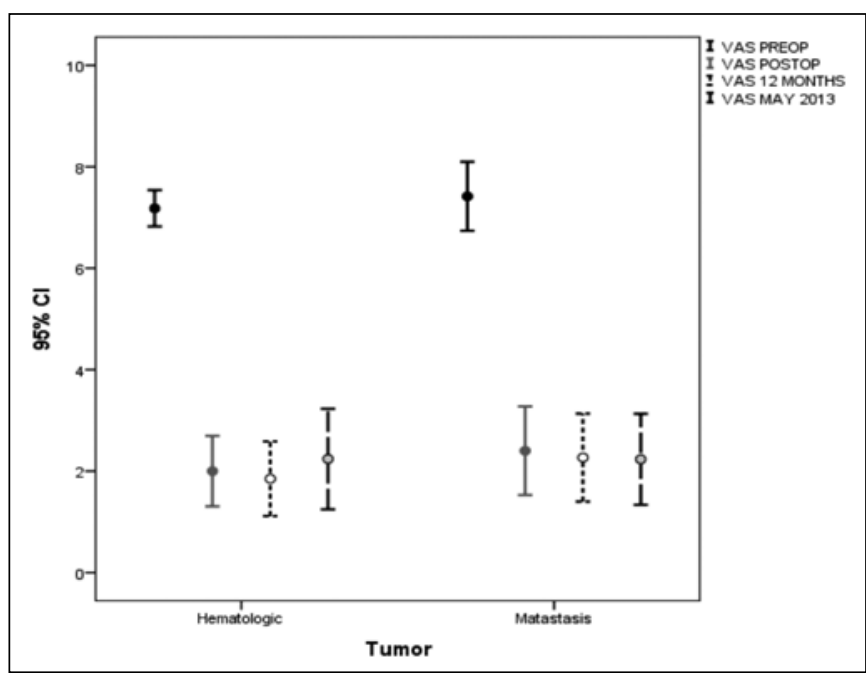

Table II: Evolution of VAS scores through the follow-up in the two groups.

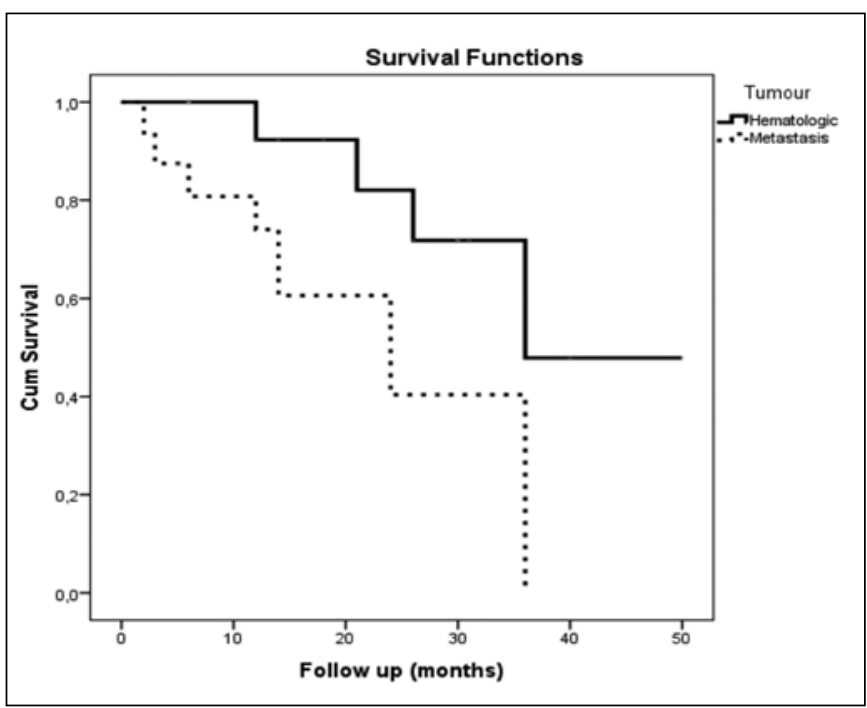

Table IV: Kaplan-Meyer Survival curves for the two groups. confidence interval (95\%) of 29.6-47, and the metastasis group had an average survival of 22.8 with a confidence interval (95\%) of 15.9-29.7 (Table IV).

Three patients died within the first 2-6 months after VCF. In total, 13 patients died across the period of study, and their average follow-up time was 14.9 (2-36) months. The remaining 19 patients had 33 VCFs and, at present, are still alive and actively being followed up. The current follow-up time is 21.2 (6-50) months.

\section{Height Restoration Analyses}

The average preoperative anterior height of the vertebral body was $19.6 \pm 4.2 \mathrm{~mm}$. This anterior height increased an average of $6.2 \mathrm{~mm}(31.6 \%)$ postoperatively, and this increase was stable over the follow-up period as evidence by the average height of $25.5 \mathrm{~mm}$ at the 12-month follow-up. The differences between the preop, postop and 12-month heights were statistically significant $(p<0.01)$ (Table V).

The average preoperative central height was $16.7 \pm 7.8 \mathrm{~mm}$. Postoperatively, this height increased by $5.8 \mathrm{~mm}$ (34.7\%), which reflected a statistically significant difference $(p<0.001)$. This increased height remained stable at the 12-month followup (Table V).

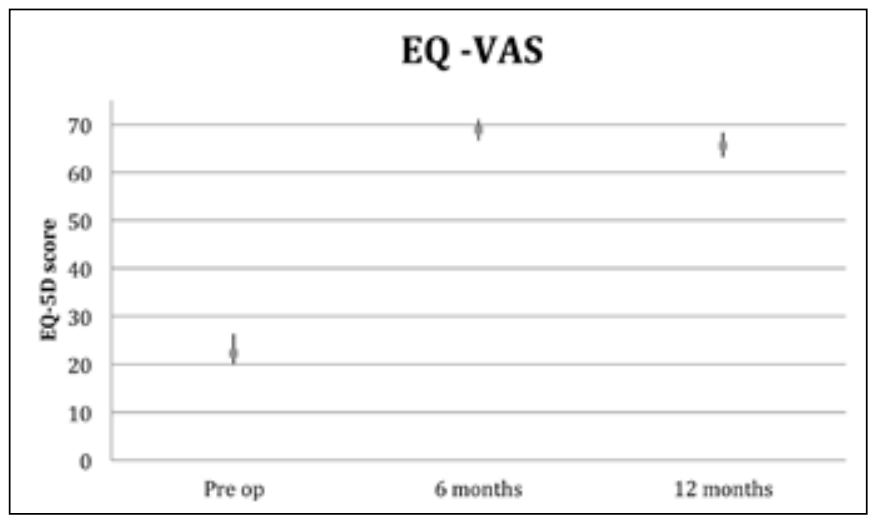

Table III: Quality of life values (preop, postop, and 12 months postop).

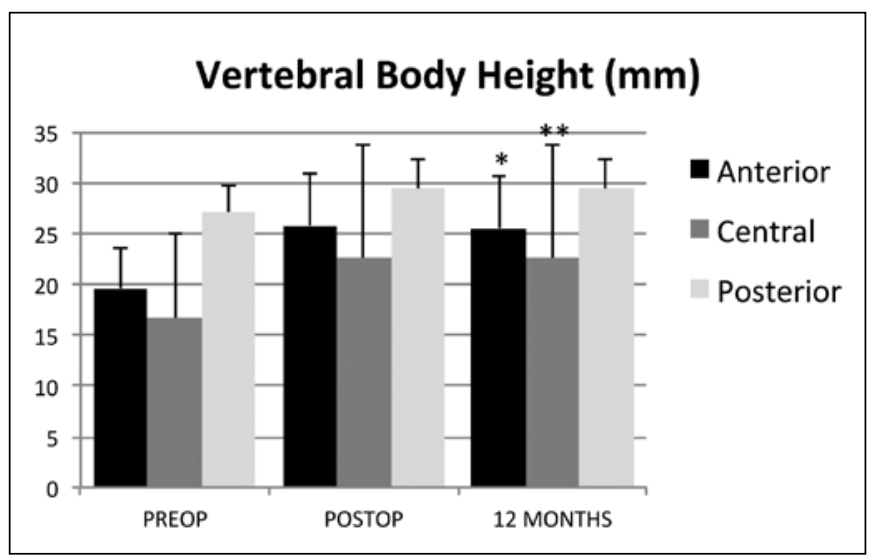

Table V: Preop, postop and 12 months follow-up anterior, central and posterior heights. 
The increase of the posterior height value between the preop and postop was only $2.4 \mathrm{~mm}(8.8 \%)$. This value did not change at the 12-month follow-up (Table V).

\section{Regional Cobb Angle}

The average preoperative regional Cobb angle was $9.1^{\circ}$ $\left(5.1^{\circ}-11.1^{\circ}\right)$, which was reduced by $3.2^{\circ}$ postoperatively to an average value of $5.9^{\circ}\left(4.9^{\circ}-7.8^{\circ}\right)(\mathrm{p}<0.05)$ and was stable at the 12-month follow-up $\left(6.1^{\circ}\right.$; range: $\left.4.9^{\circ}-7.9^{\circ}\right)$.

\section{Complications}

Cement leakage occurred in 5 of the 52 levels (9.6\%); 4 of these cases were diagnosed by plain X-Rays, and 1 was diagnosed by high definition CT scan. Two of the leakages were located in the disc space, and three were located in the paravertebral soft tissues. No leakage was found in the spinal canal. There was no symptomatic leakage.

Regarding the analyses of the risk factors for leakage, there was no statistically significant difference between the single and multilevel cases. The 2 multilevel leakage cases represented $40 \%$ of the total number of leakages. The numbers of leakages were not different across tumor types ( 2 cases among the hematologic disease group and 3 cases among the metastatic disease group).

Adjacent fractures within the follow-up period were diagnosed in 3 patients $(9.4 \%)$. All of these fractures occurred in patients with metastatic disease, but there was no statistically significant difference between the disease groups. However, it should be noted that average survival of the patients with hematologic disease was longer (38.3 months; range: 29.647.0) than that of the metastatic disease group (22.79 months; range: 15.9-29.7). There were no cases of vertebral body recollapse in this study (Figure 3A-D).

\section{DISCUSSION}

Cancer treatment and diagnosis has evolved in the past decade, and this evolution has increased the life expectancies and quality of life of patients $(19,20)$. Vertebral compression fractures related to cancer infiltration of the vertebral body are a major problem for this group of patients because they cause severe deterioration in quality of life (34). The cementoplasty technique has been widely used for pain control, but complications from either VP or KP, although uncommon, can be serious. Both techniques are efficient, but focus on controlling pain and not on controlling the biomechanical consequences of VCF $(1,14,20,32)$. Kyphoplasty, compared with conservative treatment or vertebroplasty, allows at best an additional restoration of the vertebral height and of the kyphosis angle (16). Both Verlaan and Voggenreiter have demonstrated that part of the restored height is lost when deflating the balloon prior to the cement injection (38, 39). Therefore, new methods like this intravertebral implant technique, has a clear advantage in keeping the height restoration until the stabilizing cement has been injected. Also a direct action on the endplates would be desirable to restore anatomy instead of relying on the ligamentotaxis effect.

Pain control has been the primary objective of all previous studies. In this study pain was reduced by an average of 5.3 postoperatively and 4.9 at the final follow-up $(p<0.005)$. This reduction of $74 \%$ is within the range of the results of the majority of previously published articles $(12,25,29,32)$ at 1-month follow-ups. At the 6-month follow-up, the results remained stable $(5,21)$; our study entailed longer follow-up periods for the majority of the patients (i.e., 38.2 months for the hematologic and 22.8 for the metastatic patients). Dudeney (10) reported improvements in the bodily pain of 18 myeloma patients as measured by SF36 (10), but the followup period of this study averaged only 7.4 months. Eleraky et al. (11) reported a VAS score improvement of 4.9 at the 12-month follow-ups of a retrospective group of 14 patients

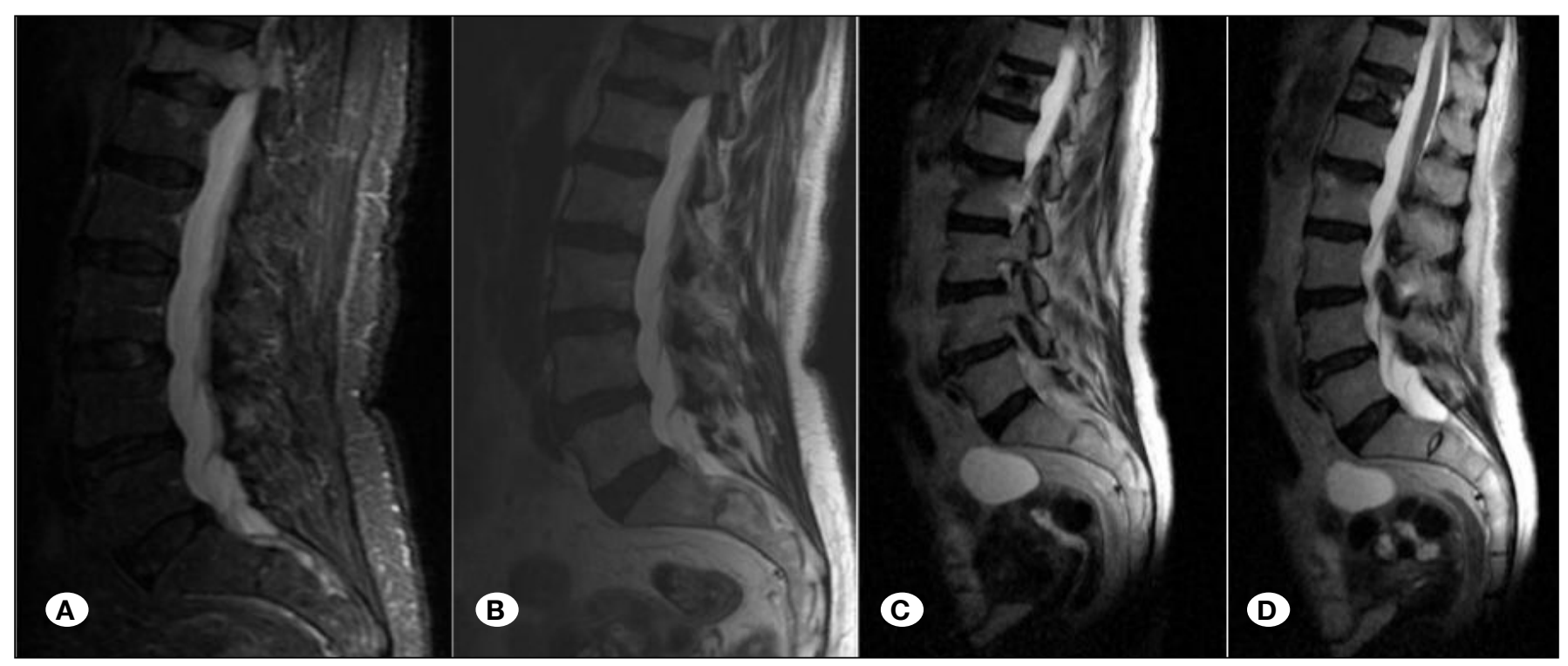

Figure 3: Multiple myeloma patient. Fracture at T12 level. A, B) Preoperative T2 weighted sagittal MRI; C, D) Postoperative $2^{\text {nd }}$ year T2 weighted sagittal MRI. 
with 30 vertebra body levels involved. Georgy (14) only reported leakage in 28 malignant VCFs and did not mention VAS scores. Zhonglai (41) followed patients for 2 years and found an average improvement of 3.6 on the VAS that was stable throughout the follow-up period of that study. At the end of our study (June 2013), the improvements in the VAS remained unchanged in the series and statistically improved compared to the preop values.

The quality of life of our group of patients, as measured with the EQ5-VAS, increased from 22.3 to 68.9 at the 6 -month follow-up $(p<0.005)$, At the 12-month follow-up, the quality of life was reduced to 65.6; this reduction was mainly attributable to general disease progression. Dudeney (10) reported improvements in quality of life as measured with short form-36 (SF-36) at a 7.4-month follow-up, but no mention was made of a longer follow-up period. Eleraky et al. (11) did not report on quality of life, but Oswestry scores were measured to an average follow-up of 16 months and showed clear improvements. As Montagu et al. (32) stated in 2012, there are few reports about the qualities of life of patients with malignant VCFs.

None of our cases died within the first 30 days $(21,32)$ after surgery; thus retrospective study of the entire group allowed us to reach conclusions about the long-term outcomes of this minimally invasive treatment in well-selected patients with pathological VCFs. None of the deaths that occurred in the course of this study were related to the surgical procedure or the technique. In all cases, these deaths were related to the progression of the primary disease.

Height restoration analyses revealed statistically significant improvements in anterior heights $(6.2 \mathrm{~mm} / 31.6 \%)$, central heights $(5.8 \mathrm{~mm} / 34.7 \%)$ and posterior heights $(2.4 \mathrm{~mm} / 8.8 \%)$. These improvement in vertebral body reduction resulted in Cobb regional angle reductions of $3.2^{\circ}$ at postop and $2.9^{\circ}$ at the 12-month follow-up. The differences between these values at preop and at every follow-up were statistically significant $(p<0.005)$. Georgy (14) did not evaluate any measures of height in 2012. In a review of the cementoplasty technique in 2011, Aghayev et al. (1) reported height increases with BKPs between 2-4 mm; although this author suggests that sagittal balance corrections are beneficial in avoiding complications, this review does not report on Cobb angle reductions. Zonglai (41) reported benefits in terms of both height increases greater than $30 \%$ (no absolute values are reported) and Cobb angle reduction of approximately $8^{\circ}$ at a 2-year follow-up.

The complications can be divided in two groups: shortterm (i.e., cement leakages and pulmonary embolisms), and long-term (i.e., adjacent fractures, regional kyphosis, disc degeneration and vertebral body re-collapse). The cement leakage ratios were within the lower margin of the various relevant publications, which range from 4 to $72.5 \%(4,8,10$, $11,14,24,32)$. In our series, none of the leakages were located in the spinal canal or the foraminal area. Cement leakage ratios in patients with spinal metastases are typically higher than the quoted ratio due to the osteolysis of the VB in pathological fractures $(6,15,17,31,35)$. The use of high viscosity cement (400 mPA) and two titanium implants that act as a guiding frame may be the main factors responsible for obtaining a horse-shoe pattern of cement distribution and avoiding high leakage ratios. This finding should be investigated in further cadaveric and clinical studies.

The multidisciplinary approach to the treatment of patients with spinal metastases and greater than 5-year life expectancies, particular those patients with hematologic diseases ( 3 , $19,20,23)$, revealed the important role of a minimal invasive technique that controls pain and minimizes biomechanical complications by achieving vertebral body anatomical reduction. This technique can avoid future deformities, new fractures, and long-term increases in pain.

The limitations of our study included its retrospective nature, the consecutive patients, and the absence of a non-reduction control group.

\section{CONCLUSION}

The present study indicated that anatomical restoration (i.e., cortical ring reduction plus endplate rebalancing) is potentially beneficial to a well-selected group of patients with spine metastases and long life expectancies because it avoids the complications typical of these types of treatments (i.e., leakage, adjacent fractures and re-collapse).

Prospective, blinded, randomized studies could enhance the understanding of the benefits of cementoplasty and vertebral body reduction in the control and management of painful, malignant vertebral body fractures.

\section{ACKNOWLEDGMENT}

David Cesar NORIEGA and Francisco ARDURA are consultants for Vexim, Antonio KRÜGER is consultant for Vexim, Dfine, Biomet, and Medtronic.

\section{- REFERENCES}

1. Aghayev K, Papanastassiou I, Frank Vrionis F: Role of vertebral augmentation procedures in the management of vertebral compression fractures in cancer patients. Current Opinion in Supportive and Palliative Care 5:222-226, 2011

2. Anderson SR: Vertebroplasty. Pain Pract 1:46-52, 2001

3. Barlogie B: Treatment of multiple myeloma. Blood 103:20-32, 2004

4. Bassem G: Feasibility, safety and cement leakage in vertebroplasty of osteoporotic and malignant compression fractures. Pain Phys 15:223-228, 2012

5. Buchbinder R, Osborne RH, Ebeling PR, Wark JD, Mitchell P, Wriedt C, Graves S, Staples MP, Murphy B: A randomized trial of vertebroplasty for painful osteoporotic vertebral fractures. N Engl J Med 361:557-568, 2009

6. Chen KY, Ma HI, Chiang YH: Percutaneous transpedicular vertebroplasty with polymethylmethacrylate for pathological fracture of the spine. J Clin Neurosci 16:1300-1304, 2009

7. Coleman RE: Skeletal complications of malignancy. Cancer 80 (Suppl 8):1588-1594, 1997

8. Cortet B, Cotten A, Boutry N, Dewatre F, Flipo RM, Duquesnoy B, Chastanet P, Delcambre B: Percutaneous vertebroplasty in patients with osteolytic metastases or multiple myeloma. Rev Rhum Engl Ed 64:177-183, 1997 
9. Dolan P, Luo J, Pollintine P, Landham PR, Stefanakis M, Adams MA: Intervertebral disc decompression following endplate damage. Spine 38(17):1473-1481, 2013

10. Dudeney S: Kyphoplasty in the treatment of osteolytic vertebral compression fractures as a result of multiple myeloma. J Clin Oncol 20:2382-2387, 2002

11. Eleraky M, Papanastassiou I, Setzer M, Baaj A, Tran N, Vrionis F: Balloon kyphoplasty in the treatment of metastatic tumors of the upper thoracic spine. J Neurosurg Spine 14:372-376, 2011

12. Fourney DR, Schomer DF, Nader R, Chalan-Fourney J, Suki D, Ahrar K, Rhines LD, Gokaslan Z: Percutaneous vertebroplasty and kyphoplasty for painful vertebral body fractures in cancer patients. J Neurosurg 98 Suppl 1: 21-30, 2003

13. Gaitanis IN, Hadjipavlou AG, Katonis PG, Tzermiadianos MN, Pasku DS, Patwardhan AG: Balloon kyphoplasty for the treatment of pathological vertebral compressive fractures. Eur Spine J 14:250-260, 2005

14. Georgy BA: Vertebroplasty technique in metastatic disease. Neuroimaging Clin N Am 20:169-177, 2010

15. Gerszten PC, Monaco EA $3^{\text {rd }}$ : Complete percutaneous treatment of vertebral body tumors causing spinal canal compromise using a transpedicular cavitation, cement augmentation, and radiosurgical technique. Neurosurg Focus 27:E9, 2009

16. Hargunani R, Le Corroller T, Khashoggi K, Murphy KJ, Munk PL: Percutaneous vertebral augmentation: The status of vertebroplasty and current controversies. Semin Musculoskelet Radiol 15:117-124, 2011

17. Harrington KD: Major neurological complications following percutaneous vertebroplasty with polymethylmethacrylate: A case report. J Bone Joint Surg Am 83-A:1070-1073, 2001

18. Hulme PA, Krebs J, Ferguson SJ, Berlemann U: Vertebroplasty and kyphoplasty: A systematic review of 69 clinical studies. Spine 31:1983-2001, 2001

19. Hussein MA: Multiple myeloma: Present and future. Curr Opin Oncol 14:31-35, 2002

20. Hussein MA: The role of vertebral augmentation in multiple myeloma: International myeloma working group consensus statement. Leukemia 22:1479-1484, 2008

21. Kallmes DF, Comstock BA, Heagerty PJ, Turner JA, Wilson DJ, Diamond TH, Edwards R, Gray LA, Stout L, Owen S, Hollingworth W, Ghdoke B, Annesley-Williams DJ, Ralston $\mathrm{SH}$, Javuik JG: A randomized trial of vertebroplasty for osteoporotic spinal fractures. N Engl J Med 361:569-579, 2009

22. Kallmes DF, Schweickert PA, Marx WF, Jensen ME: Vertebroplasty in the mid- and upper thoracic spine. AJNR Am J Neuroradiol 23:1117-1120, 2002

23. Katzel JA: Multiple myeloma: Charging toward a bright future. Cancer J Clin 57:301-318, 2007

24. Klazen CA, Lohle PN, de Vries J, Jansen FH, Tielbeek AV, Blonc MC, Venmans A, van Rooji WF, Schoemaker MC, Jutmann JR, LoTH, Verahaar HJ, van Der Graaf Y, van Everding KJ, Muller AF, Elqersma OE, Halkema DR, Fransen $H$, Janssens $X$, Buskens E, Mali WP: Vertebroplasty versus conservative treatment in acute osteoporotic vertebral compression fractures (Vertos II): An open-label randomised trial. Lancet 376: 1085-1092, 2010

25. Kose KC, Cebesoy O, Akan B, Altinel L, Dincer D, Yazar T: Functional results of vertebral augmentation techniques in pathological vertebral fractures of myelomatous patients. $\mathrm{J}$ Natl Med Assoc 98: 1654-1658, 2006

26. Krüger A, Baroud G, Noriega D, Figiel J, Dorschel C, Ruchholtz $S$, Oberkircher L: Height restoration and maintenance after treating unstable osteoporotic vertebral compression fractures by cement augmentation is dependent from the cement volume used. Clin Biomech (Bristol Avon) 28(7):725730, 2013

27. Krüger A, Oberkircher L, Figiel J, Floßdorf F, Bolzinger F, Noriega DC, Ruchholtz S: Height restoration of osteoporotic vertebral compression fractures using different intravertebral reduction devices: A cadaveric study. Spine J 15(5):10921098, 2015

28. Lemke DM: Metastatic compression fractures: Vertebroplasty for pain control. J Neurosci Nurs 35:50-55, 2003

29. Masala S, Anselmetti GC, Marcia S, Massari F, Manca A, Simonetti G: Percutaneous vertebroplasty in multiple myeloma vertebral involvement. J Spinal Disord Tech 21:344-348, 2008

30. Mavrogenis AF: Posterior decompression and stabilization, and surgical vertebroplasty with the vertebral body stenting for metastatic vertebral epidural cauda equina compression. J Surg Oncol 101:253-258, 2010

31. McGirt MJ, Parker SL, Wolinsky JP, Witham TF, Bydon A, Gokaslan ZL: Vertebroplasty and kyphoplasty for the treatment of vertebral compression fractures: An evidence-based review of the literature. Spine J 9:501-508, 2009

32. Montagu A, Speirs A, Baldock J, Corbett J, Gosney M: A review of vertebroplasty for osteoporotic and malignant vertebral compression fractures. Age and Aging 41:450-455, 2012

33. Pflugmacher R, Beth P, Schroeder RJ, Schaser KD, Melcher I: Balloon kyphoplasty for the treatment of pathological fractures in the thoracic and lumbar spine caused by metastasis: Oneyear follow-up. Acta Radiol 48:89-95, 2007

34. Saad F, Lipton A, Cook R, Chen YM, Smith M, Coleman R: Pathologic fractures correlate with reduced survival in patients with malignant bone disease. Cancer 110:1860-1867, 2007

35. Saliou G, Kocheida el M, Lehmann P, Depriester C, Paradot G, LeGars D, Balut A, Deramond H: Percutaneous vertebroplasty for pain management in malignant fractures of the spine with epidural involvement. Radiology 254:882-890, 2010

36. Silverman SL: The clinical consequences of vertebral compression fracture. Bone 13 Suppl 2:S27-31, 1992

37. Tzermiadianos M, Renner S, Phillips F, Hadjipavlou A, Zindrick M, Havey R, Voronov M, Patwardhan A: Altered disc pressure profile after an osteoporotic vertebral fracture is a risk factor for adjacent vertebral body fracture. Eur Spine J 17(11): 15221530, 2008

38. Verlaan J, van de Kraats E, Oner F, van Walsum T, Niessen W, Dhert W: The reduction of endplate fractures during balloon kyphoplasty. Spine 30(16):1840-1845, 2005

39. Voggenreiter G: Balloon kyphoplasty is effective in deformity correction of osteoporotic compression fractures. Spine 30(24):2806-2812, 2005

40. Yuan HA, Brown CW, Phillips FM: Osteoporotic spinal deformity: A biomechanical rationale for the clinical consequences and treatment of vertebral body compression fractures. J Spinal Disord Tech 17(3):236-242, 2004

41. Zhonglai Q: Kyphoplasty for the treatment of malignant VCF caused by metastases. J Clin Neurosci 18:763-767, 2011 